BULLETIN Bulletin hispanique

HISPANIQUE Université Michel de Montaigne Bordeaux

114-1 | 2012

Varia

Gabriele Morelli (éd.), Epistolario inédito sobre Miguel Hernández [1961-1971] entre Dario Puccini y Josefina Manresa

Espuela de Plata, Sevilla, 2011

Jacques Issorel

(2) OpenEdition

Journals

Édition électronique

URL : http://journals.openedition.org/bulletinhispanique/1968

DOI : 10.4000/bulletinhispanique.1968

ISSN : $1775-3821$

Éditeur

Presses universitaires de Bordeaux

Édition imprimée

Date de publication : 1 juin 2012

Pagination : 491-492

ISBN : 978-2-86781-812-7

ISSN : 0007-4640

Référence électronique

Jacques Issorel, « Gabriele Morelli (éd.), Epistolario inédito sobre Miguel Hernández [1967-1971] entre Dario Puccini y Josefina Manresa », Bulletin hispanique [En ligne], 114-1 | 2012, mis en ligne le 27 mai 2013, consulté le 23 septembre 2020. URL : http://journals.openedition.org/bulletinhispanique/1968 ; DOI : https://doi.org/10.4000/bulletinhispanique.1968

Ce document a été généré automatiquement le 23 septembre 2020.

Tous droits réservés 


\section{Gabriele Morelli (éd.), Epistolario inédito sobre Miguel Hernández [1961-1971] entre Dario Puccini y Josefina Manresa}

Espuela de Plata, Sevilla, 2011

Jacques Issorel

\section{RÉFÉRENCE}

Gabriele Morelli (éd.), Epistolario inédito sobre Miguel Hernández [1961-1971] entre Dario Puccini y Josefina Manresa. - Sevilla, Espuela de Plata, 2011, 144 p.

1 La correspondance entre Josefina Manresa, veuve de Miguel Hernández, et l'hispaniste italien Dario Puccini couvre dix années (1961-1971), au cours desquelles ce dernier, déjà auteur de plusieurs études sur le poète et aussi du Romancero della Resistenza spagnola (1960 ; éd. espagnole, 1967, 1982), publie Miguel Hernández. Poesie (1962) et Miguel Hernández. Vita e poesia (1966). Dans ces 47 lettres, soigneusement annotées, on voit les deux correspondants envisager l'œuvre du poète levantin sous des angles parfois divergents. Comme l'explique très clairement dans son introduction Gabriele Morelli, la veuve exprime sa «voluntad [...] de separar la vida (y sobre todo la experiencia íntima que compartió con Miguel) de la obra literaria » (p. 33). Ce faisant, elle entre en conflit (mais de façon cordiale et mesurée) avec la "exigencia investigadora de Puccini, que, al contrario, busca en los actos y momentos concretos de la biografía el legado espiritual para explicar su poesía » (p. 34).

2 Dans l'Espagne franquiste des années 60, il n'était pas facile d'être la veuve d'un «rouge », et encore moins, d'un «rouge» célèbre. Aussi voit-on, au fil des lettres, Josefina défendre l'image d'un Miguel étranger à la politique ( Lo presentan a Miguel un político, que él no lo era», p. 75), mais simplement «humano» et «bueno»(ibid.). 
Pareillement, elle réfute les «inventos » de deux biographes du poète, Concha Zardoya et Elvio Romero, et encore plus la brève liaison de celui qui était encore son fiancé, avec Maruja Mallo à Madrid en 1935 ("Lo de la pintora [...] es una tontería que no existió", p. 75). Elle fait preuve d'un semblable acharnement pour obtenir des éditeurs italiens Feltrinelli et Lerici les meilleures conditions financières possibles. Elle est aidée en cela par Puccini, qui ne ménage pas sa peine et défend ses intérêts avec une constante sollicitude. Malgré les « largas vicisitudes y dificultades » (p. 62), il intervient auprès des éditeurs, négocie, obtient que des poèmes de Miguel Hernández soient lus à la télévision italienne. Sa lettre de septembre 1964 ( $\left.n^{\circ} 12\right)$ ne contient pas moins de cinq projets, fruits d'une passion et d'un enthousiasme qui l'amènent à écrire : « La obra de Miguel que quiero hacer conocer a todo el mundo", p.90). C'est lui qui sert d'intermédiaire pour que la revue romaine Studi di Letteratura Spagnola publie en 1966 dix sonnets inédits du cycle El silbo vulnerado. Le texte de ces sonnets est inclus dans la lettre de Josefina Manresa du 22 février 1966 (p. 80-89) et fait l'objet d'un va-et-vient entre Elche et Rome, car Josefina les a copiés à la main et Puccini, avec une minutie exemplaire, tient à s'assurer du moindre détail.

Parmi toutes ces lettres, la dernière de Josefina Manresa ( $\left.{ }^{\circ} 47\right)$, écrite à Elche le 10 octobre 1971, est assurément la plus intéressante. Josefina demande d'abord à son correspondant d'éliminer dans la deuxième édition de son livre Miguel Hernández. Vita e poesia la "página 100 a partir de "el mayor interés del drama consiste en el material autobiográfico" » (p. 123). Le drame en question est Pastor de la muerte. On y voit le berger Pedro décidé à aller combattre " por un porvenir libre y claro ", mais retenu par sa mère, sa sœur et surtout sa fiancée, qui, dans un suprême sacrifice, se donne à lui pour qu'il renonce à partir. Pedro, non seulement ne revient pas sur sa décision, mais à sa fiancée qui lui reproche en pleurant de l'avoir déshonorée, il répond qu'entre deux êtres qui s'aiment il n'y a pas de déshonneur et que l'amour n'a que faire de la " permission des juges et des prêtres» (p. 26). Se voir ainsi assimilée à la fiancée consentante par le critique italien ne pouvait qu'éveiller l'indignation de la veuve, qui ajoute quelques lignes plus bas : « Para mí un beso del novio era perder el honor » (p. 124).

4 Les lettres publiées par Gabriele Morelli offrent un grand intérêt, car elles éclairent d'un jour nouveau certains aspects de l'œuvre de Miguel Hernández et révèlent, à la fois, une femme attachée à sauvegarder, dans un contexte politique hostile, l'image de l'homme qu'elle a aimé, et celle d'un chercheur scrupuleux, serviteur zélé et généreux d'une œuvre dont il a contribué avec talent à assurer la pérennité. 